\title{
Is the trend your friend? \\ An analysis of technology 4.0 investment decisions \\ in Agricultural SMEs
}

\author{
Maria Carmela Annosi \\ Wageningen University \& Research \\ Department of Business Management and Organization \\ Federica Brunetta* \\ LUISS Guido Carli University \\ Department of Business and Management
}

\author{
Alberto Monti \\ Bocconi University \\ Department of Management and Technology and ASK Research Center
}

\section{Francesco Nati}

\begin{abstract}
Smart Agriculture and 4.0 technologies have brought several benefits to agricultural small and medium enterprises (SMEs). Nonetheless, the penetration of such digital technologies is still poor and slow. This study addresses the issue and provides some insights on the reasons related to the still limited adoption of 4.0 technologies within agricultural SMEs. Authors do not simply focus on the adoption per se, but rather devote attention to the SMEs owners/managers' subjective perception of the opportunity behind the technology adoption, and of the incentives or constraints given by the external environment as well as the organizational capabilities as embedded in the owners/managers' skills and organizational routines. Authors analyze data collected by surveying 96 Italian agricultural SMEs owners/managers, and empirically confirm the relevance of managerial capabilities, managerial cognition, and managerial perception of the external environment for the adoption of 4.0 technologies in agricultural SMEs.

The results of this research support the conclusion that organizational capabilities related to the search for evidence-based knowledge by the SME's decision-maker are crucial for the technology's adoption. In addition, we show the statistical significance relevance of the managerial perception of technological usefulness and of the availability of a supporting business environment either in the form of professional services or institutional support, on the technology's adoption. The article ends by discussing the results and highlighting relevant managerial implications.
\end{abstract}

\section{Keywords}

Smart Agriculture; 4.0 technologies adoption; Agri-food; SMEs; managerial capabilities; managerial cognition; managerial perception

\footnotetext{
*Corresponding Author

Federica Brunetta, Ph.D.

LUISS Guido Carli University

Department of Business and Management

Viale Romania, 32

00197, Rome (I)

fbrunetta@luiss.it -+390685225438
} 


\title{
Is the Trend your Friend? \\ An Analysis of Technology 4.0 Investment Decisions in Agricultural SMEs
}

\begin{abstract}
Smart Agriculture and 4.0 Technologies have brought several benefits to agricultural small and medium enterprises (SMEs). Nonetheless, the penetration of such digital technologies is still poor and slow. This study addresses the issue and provides some insights on the reasons related to the still limited adoption of 4.0 technologies within agricultural SMEs. Authors do not simply focus on the adoption per se, but rather devote attention to the SMEs owners/managers' subjective perception of the opportunity behind the technology adoption, and of the incentives or constraints given by the external environment as well as the organizational capabilities as embedded in the owners/managers' skills and organizational routines. Authors analyze data collected by surveying 96 Italian agricultural SMEs owners/managers, and empirically confirm the relevance of managerial capabilities, managerial cognition, and managerial perception of the external environment for the adoption of 4.0 technologies in agricultural SMEs.

The results of this research support the conclusion that organizational capabilities related to the search for evidence-based knowledge by the SME's decision-maker are crucial for the technology's adoption. In addition, we show the statistical significance relevance of the managerial perception of technological usefulness and of the availability of a supporting business environment either in the form of professional services or institutional support, on the technology's adoption. The article ends by discussing the results and highlighting relevant managerial implications.
\end{abstract}

\section{Keywords}

Smart Agriculture; 4.0 technologies adoption; Agri-food; SMEs; managerial capabilities; managerial cognition; managerial perception 


\section{Is the Trend your Friend? \\ An Analysis of Technology 4.0 Investment Decisions in Agricultural SMEs}

\section{Introduction}

The agricultural industry is undergoing the digital transformation. Many effects are already visible, such as a growing use of smart technologies and big data analytics, which promise to lead to higher efficiency, and better quality of production. Digital transformation is also leading to the rise of agreements for value co-creation with companies and supply chain partners who rethink their operations, controls, and coordination of activities.

Smart Agriculture is an approach to farm management that utilizes the so-called " 4.0 Technologies" to maximize economic returns and to guarantee the preservation of resources, while at the same time protecting the environment (Maddalena, 2015). These technologies include: Artificial Intelligence (Kaplan \& Haenlein, 2019), Big Data analytics (McAfee \& Brynjolfsson, 2012), Cloud Computing (Sultan, 2011), CyberPhysical Systems (computer-based algorithms) (Khaitan \& McCalley, 2015), Information and Communication Technologies (FAO, 2017) and finally, the Internet of Things (Kranz, 2017).

Smart agriculture is often referred to as the Fourth Agricultural Revolution (Deloitte, 2016), given its extensive benefits and prospective economic impacts. The use of 4.0 technologies reduces the environmental impacts and improves productivity and profits at once (Accenture, 2017; Smith, Dhuyvetter, Kastens, Kastens, \& Smith, 2013; Shockley, Dillon, Stombaugh \& Shearer, 2012; Shockley, Dillon, \& Stombaugh, 2011).

In this work, we take into consideration different types of applications of the 4.0 technologies for smart agriculture (XLabs, 2017) and specifically: (i) Smart irrigation and input delivery; (ii) Agriculture drones or Unmanned Aerial Vehicles (UAVs) (Anderson, 2014); (iii) Soil and plants monitoring systems (Van Es \& Woodard, 2017); (iv) Yield Monitoring Systems; (v) Farm Management Software (FMSs) and Predictive Data Analytics (Consolo \& D'Amico, 2017); (vi) Precision livestock systems, (vii) Smart greenhouses. These technologies possess the potential to make farms' production systems more sustainable, efficient and resilient. In fact, they enable and increase crop yield, an early detection of diseases, pests or weeds for a timely and site-specific control, an optimization of crop irrigation. Additionally, these technologies affect the possibility to fertilize according to real needs, monitoring and control of in-farm machines and equipment, and the storing of historical data (De Clercq, Vats \& Biel, 2018). Thus, they provide new insights to improve the management decision-making and the total traceability of the process.

Scholars are increasingly focusing on the adoption of 4.0 technologies in the agricultural industry, especially for small and medium-sized enterprises (SMEs). Understanding why and how SMEs in agricultural sector adopt technological innovations, and more specifically digital technology, is crucial for ensuring a successful adoption process (Swanson \& Wang, 2005), especially since many studies report many unsuccessful information technology (IT) implementations or even low rates of adoption (Acar, Kocak, 
Sey \& Arditi, 2005; Shin, 2006; Southern \& Tilley, 2000).

Past studies have identified both managerial and organizational drivers able to explain why firms adopt IT solutions (e.g. Premkumar, Ramamurthy, \& Crum, 1997; Desai, Wright, \& Fletcher, 1998; Teo \& Pian, 2003). Among them, previous research has identified the following relevant factors: (i) the managerial support of the adoption of technologies (e.g., Soliman \& Janz, 2004); (ii) the presence of leading actors, so called "champions", fostering and supporting technological changes (e.g., Sharma \& Rai, 2003); (iii) the level of education with respect to technologies (Premkumar, Ramamurthy, \& Nilakanta, 1994); (iv) their implementation (e.g., reactivity, leadership, weakness, etc. see.., Swanson \& Ramiller, 1997; Teo \& Pian, 2003); (v) the relevance of technological integration in the light of strategic plans (Fletcher \& Wright, 1995); vi) and the size of the firm (Young, Carr, \& Rainer, 1999). Scholars have also looked at the presence of related technologies, or the inertia created by existent technologies, as potential incentives - or disincentives - for technology adoption (Hovav, Patnayakuni, \& Schuff, 2004). Organizational culture has also been identified as a key element (Fink, 1998), especially in the light of potential facilitators of adoption such as orientation towards innovation, conflict absence, communication, and flexibility (Powell \& Dent-Micallef, 1997).

Few studies, however, analyze the adoption's drivers of specific technologies in SMEs (e.g. Premkumar, 2003; Riemenschneider, Harrison, \& Mykytyn, 2003). Among them, the vast majority takes qualitative and exploratory approaches (Wheeler, 2008; Long, Blok, \& Coninx, 2016), analyzing the impact of new technologies on the SMEs business model (Griffith, Heydon, Lamb, Lefort, \& Taylor, 2013; Long, Blok, \& Poldner, 2017) or focusing on the implementation stage (DeLone, 1988; Gable, 1991) with little empirical research on the determinants of IT adoption in SMEs.

Those studies that develop a statistical analysis of the factors influencing smart agriculture adoption (e.g., Adrian, Norwood, \& Mask, 2005; Castle, Lubben, \& Luck, 2016), focus their research on different variables such as farmer's age, farm income, use of a cell phone with internet access, computer confidence, soil quality, tenure ownership, etc. Additionally, they tend to be geographically limited to the United States or to the cotton production industry (Larson, et al., 2008; Paxton, et al., 2010; Walton, et al., 2010). Even if they represent a further step in the understanding of the drivers of smart agricultural adoption, these works do not consider the peculiarities of SMEs that are likely to use highly centralized structures. In particular, in context where the SMEs owners/managers are the one taking the most critical decisions while adopting a generalist approach in the employment of their human resources and thus lacking a set of knowledge skills, and attitudes useful to identify and pursue new opportunities (Blili \& Raymond, 1993).

Indeed, mainstream literature reports that SMEs owner/managers hardly take part in formal learning activities, have limited or no access to peers or role models within the company, do not have time and financial slack at their disposal, and rely on external contacts (Jones \& Macpherson, 2006; Kotey \& Folker, 2007).

Therefore, the crucial role of SMEs owners/managers and their possible lack of competencies demand for a focus on the organizational capabilities to acquire information, the SMEs owners/managers' cognition, and the external incentives potentially enabling the development of their competence.

Scholars have also reported that an integration of environmental features and stimuli, organizational capabilities and managerial cognition may give a better explanation of 
strategic action (Johnson \& Hoopes, 2003), so it is necessary to deepen our understanding of how these factors influence the owner/manager's adoption of a new IT solution.

We build on and extend previous literature by integrating three aspects - managerial cognition, organizational capabilities and environmental incentives- related to the adoption of IT technologies in SME therefore answering the call for a more comprehensive explanation of SMEs owner/manager strategic action. Hence, the purpose of this study is to answer the following research questions: Which are the determinants of technology adoption in agricultural SMEs? What role do organizational capabilities, managerial cognition and external incentives play in the investment decision?

We specifically address these questions by devoting attention to the SMEs owners/managers' subjective perception of the opportunity behind the technology adoption, and of the incentives or constraints given by the external environment as well as the organizational capabilities as embedded in the owners/managers' skills and organizational routines. We focus on the managers, since they make sense of information for the entire firm. Many can take part in the collection of data and/or data processing, but the information that converges is interpreted at the managerial level for organizational-level action (Daft \& Weick, 1984; Thomas, Clark \& Gioia, 1993). In other words, the subjective representation of the reality that owners/managers develop determines the firm's strategic agenda (e.g., Dutton \& Jackson, 1987).

We surveyed a sample of 96 Italian Agricultural SMEs. We administered a questionnaire, through which we collected data on several factors that may influence owner/managers' decisions to invest in 4.0 technologies for smart agriculture. Our study includes micro, small and medium firms in the agricultural industry. Farms involved in the study accomplish the following activities: (i) the "production, rearing or growing of agricultural products including harvesting, milking, breeding animals and keeping animals for farming purposes"; or (ii) "maintaining the agricultural site in a condition which makes it suitable for grazing or cultivation without any particular preparatory action going beyond usual agricultural methods" (European Commission, 2015, Regulation 1782/2003, Article 2).

The remainder of this paper is as follows: we first present our theoretical background and hypotheses, and then the methods and finally we discuss our results, implications and future avenues of research.

\section{Theory development and research hypotheses}

Our study examines the enactment of technology strategy in SMEs operating in the agricultural sector, follow through the analysis of their specific form of investments, adoption of digital-based administrative or production applications, all of which having the purpose to improve the firm's products or processes. We present our theoretical model in Figure 1, while the connections and the corresponding hypotheses are explained and supported in the following sections.

During periods of technological change, when the level of uncertainty is higher, managerial cognition becomes crucial for action (Walsh, 1995). Managerial sensemaking, more specifically, becomes indeed the basis for action given the huge 
amount of (possibly conflicting) information available during technological change (Ocasio, 1997; Cho \& Hambrick, 2006).

Additionally, in case of SMEs, the owners/managers are often the central decision-makers or primal actor influencing the firm's decision-making processes (Hsu, Chen, \& Cheng 2013). This is further sustained by the fact that SMEs can rely on limited resources and capabilities in the area of information-systems, therefore the owner/managers of SMEs may be more directly involved in the information processing demands of operations (Tihanyi \& Thomas, 2005).

All these studies provide compelling arguments about the relevance of SME owner/managers' subjective representations of the reality at the moment of new technology adoption. In this paper, we consider two forms of subjective representations relevant for the decision to adopt: the perception of the opportunity behind the adoption of new technology and the aspects of the external environment that are central in the decision to adopt.

Managerial cognition therefore links a firm's actions to a changing environment by influencing what is observed and how this information is interpreted (Daft \& Weick, 1984; Ocasio, 1997). Within their firms, managers might also become ingrained in sets of routines that link capabilities and cognition together. Following Kaplan (2008), we have taken into account how managerial cognition, in the form of disposition towards the investment in new technologies, relate to the organizational capability to collect relevant related information about new technology to adopt. The underlying basis of this study is that managerial cognition and managerial capabilities are not just different justifications of the organization response, nor unrelated forces influencing the adoption of new technologies. Rather these organizational and managerial aspects are meaningfully connected and still deserve scholarly attention (McGee, 2005). This research aims to contribute to a better understanding of the relationships among the overall strategic behavior of SME as a managerial response to the opportunity to invest on a new technology, the managerial perception of the environment and the managerial capabilities.

\subsection{Capabilities that Drive the Firm's Response to a New Technological Opportunity}

We consider the adoption process as a result of the interplay between external and internal environment (Liao, Welsch, \& Stoica, 2003) and, in line with a more behavioral approach (Nelson \& Winter, 1982), argue that capabilities and routines determine whether firms survive by adapting to technological challenges, and thus perform (Sorensen \& Stuart, 2000). Routines and capabilities can create unfavorable conditions for the firms to respond to the changing context (Barnett, 1990) inhibiting the renewal of their current competencies (Leonard-Barton, 1992; Levinthal \& March, 1993).

Theories of absorptive capacity suggest that the degree of prior knowledge shapes investment decisions in a new arena (Cohen \& Levinthal, 1990). Accumulations of knowledge connected to a new technical arena could help organizations adapt over time (Mitchell \& Singh, 1992; Rosenkopf \& Nerkar, 2001).

More specifically, we argue that SMEs catch information, as well as data, documents and standards (Simmie, 2002) from their external environment, enacting a process of transformation into internal knowledge This claim is also supported by the fact that owner/managers of SMEs tend to use their contacts and relationships to collect additional information (Chell \& Baines, 2000). 
This process stands at the basis of SMEs innovation, as confirmed by Atherton and Hannon (2000), who argue that innovation in SMEs is likely a pure managerial process, since top managers or owners do assume all decisions (Stanworth \& Gray, 1992). In addition to managing daily operations, they directly affect future investment decisions regarding the adoption of technology (e.g., Fuller-Love, 2006).

Overall, these researches suggest that managerial accumulation of knowledge on the technologies should be expected to enable firm response to technical change and allocation of investment into 4.0 technological investment.

HP1: The allocation of investment into 4.0 technological innovations is positively related to the managerial activity of collection of evidence-based knowledge on those technologies.

\subsection{The Role of Managerial Cognition}

Past studies (e.g., Weick, 1995) propose that cognitive limits hinder the elaboration of a comprehensive understanding of the environment by top managers (e.g., Fiol \& O'Connor, 2003). Managers elaborate subjective representations of their environment that affect their view about events, business opportunities, and strategic decisions (Nadkarni \& Barr, 2008). Therefore, it is not the objective environment, but rather their own subjective representation, that influences a firm's strategic agenda and drives decisionmaking (Nadkarni \& Barr, 2008).

\subsubsection{Managerial Perception of the Opportunity Behind Technology Adoption}

The main basis for decision-making is causal reasoning (Fiske \& Taylor, 1991) which has an impact on the way strategic decisions are taken (Huff, 1990). During the decisionmaking process, managers develop beliefs related to the causal relationship between the firm's strategy and the environment (Nadkarni \& Barr, 2008). The cause-effect belief about the environment affects the way opportunities are interpreted and which strategic actions are triggered (e.g., Dutton, Fahey, \& Narayanan, 1983; Barr \& Huff, 1997).

One of the major limitations in the agricultural sector is the low awareness of the availability of innovations, and of their potential benefits (Rogers, 1995; Long et al., 2016). Often managers cannot build the causal relationship between the adoption of a technological solution and the firm itself (Carson \& Gilmore, 2000; Bull, 2003), or are not certain about the opportunities that the new solutions might offer (Adrian et al., 2005). Nonetheless, managers proactively looking for the newest technologies on the market may successfully adopt such innovations.

According to Shane and Venkataraman (2000) and Corbett (2005), the perception of the opportunity is the key prerequisite for any entrepreneurial action and investment. More specifically, Adrian et al. (2005) demonstrated that SMEs owners/managers who perceived a net benefit and had a higher level of confidence in smart agriculture technologies showed greater propensity to adopt them. Hence, we hypothesize:

HP2: The allocation of investment into 4.0 technological innovations is positively related to the managerial perception of the opportunity behind the technology adoption. 


\subsubsection{The Managerial Perception of the External Environment}

The external environment plays a crucial role in the adoption of new technologies (e.g., Premkumar \& Roberts, 1998). However, past studies have shown that the strategic management of technology also depends on the decision-maker's perception of the external environment, which does not mirror the objective realities of the environment (e.g., Lefebvre, Mason, \& Lefebvre, 1997). Some studies embrace the process view that the decision-maker's perception of the environment overwrites the objective measurement of the characteristics of the environment itself (Bourgeois 1980; Lefebvre et al., 1997; Jauch \& Kraft, 1986). Therefore, the perception of the external environment becomes crucial to the strategic management of technology. Traditional literature, indeed, has pointed at the key role of environmental scanning in the strategy-making process (Bourgeois 1980; Hambrick, 1981).

While looking at the external factors affecting the adoption of new technologies, past studies (Warren, 1978) have stressed the role of vertical linkages as conduits for the flow of technology to rural communities. According to Premkumar \& Roberts (1998), vertical linkages can be seen as means that provide the necessary support to adopt online data access. In general term, DeLone (1988) reported that SMEs depend on external support. Therefore, we argue that supporting infrastructures are fundamental for the management of any enterprise (Suzuki, Kim, \& Bae, 2002). Good availability of business services, such as commercial, legal, financial, but especially IT and digital consultancy, enables managers of SMEs to better focus on their core business - production - while delegating some aspects to other stakeholders, thereby attaining efficiency and specialization advantages (Ruef, 2005). In other words, in order to invest in technologies, managers need to feel sure that they have a proper supporting external environment (Long et al., 2016). Consequently:

HP3: The allocation of investment into 4.0 technological innovations is positively related to the managerial perception of the availability of a supporting business environment

\section{Material and methods}

\subsection{Setting}

Our analysis focuses on micro, small and medium firms in the agricultural industry, involved either in producing, rearing or growing agricultural products as well as harvesting, milking, breeding animals for farming purposes, for grazing or cultivation with agricultural methods (European Commission, 2015, Regulation 1782/2003, Article 2).

Several technologies are available to these firms to apply smart agriculture, and they include: (i) Artificial Intelligence, defined as the ability of a computer or robot to perform tasks autonomously, without the intervention of human beings (Kaplan \& Haenlein, 2019).; (ii) Big Data analytics, that support gathering, organizing, and analyzing data to discover trends, correlations, patterns and other valuable information (McAfee \& Brynjolfsson, 2012); (iii) Cloud Computing, enabling users to store, manage and process 
data on remote servers hosted on the internet, instead of local servers or personal computers (Sultan, 2011); (iv) Cyber-Physical Systems, that are mechanisms controlled or monitored by computer-based algorithms (Khaitan \& McCalley, 2015); (v) Information and Communication Technologies (ICT), encompassing all technologies related to telecommunication (both wireless and wired), computer technologies, audiovisual systems, storage and software, allowing users to access, store, elaborate on, and transmit, manipulate information (FAO, 2017) and finally, the (vi) Internet of Things, composed by networked physical devices that connect and exchange information and data being incorporated with sensors, connectivity, electronics and software (Kranz, 2017).

The applications of these 4.0 technologies are heterogeneous (XLabs, 2017; De Clercq, et al., 2018). First, Smart Irrigation and Input Delivery enable farmers to minimize water wastage thanks to an IoT system that constantly monitors various parameters such as soil temperature, moisture, humidity, and light to calculate the effective need for water. Usually, those kinds of systems utilize variable rate technologies (VRT) to deliver the right dosage of water, fertilizer and pesticide according to soil parameters and needs. These systems often collaborate with other types of technologies such as soil sensors, drones and weather tracking and forecasting software. Second, Agriculture Drones and Robotics are typically used for cultivation mapping and crop health monitoring. Through image recognition algorithms, they can sense, detect and categorize plant pests and diseases with an high accuracy. They can also scan vast areas of land and work with other sensors to collect a wide range of information (Anderson, 2014). Robots (or intelligent farm machines) perform several farm functions more efficiently than traditional machines such as autonomously detecting the location of ripe fruits on a trellis and pulling them off the branch. Telematics and positioning technologies, such as the Global Positioning System (GPS), are typically used for in-field machine control. Third, Soil and Plants Monitoring Systems collect data and assist farmers in monitoring the quality of soil and in avoiding its degradation. They can monitor various physical, chemical and biological soil properties (i.e. texture and water-holding). Other sensors collect more data about plant composition (microbial makeup, genetic expression, etc.) and analyze that data to improve seed research and development (Van Es \& Woodard, 2017). Fourth, Yield Monitoring Systems enable farmers to reduce the operational costs and to boost productivity by monitoring various aspects affecting agricultural yield such as moisture content, grain mass flow and total quantity of harvested grain. Fifth, Farm Management Software (FMSs) and Predictive Data Analytics include software that allow farmers to more efficiently manage their resources, crop production, farm animals, etc. (i.e. weather tracking and forecasting software). They assist farmers with information collection and management by relying on diverse sensors and tracking devices. By using Big Data and predictive analytics software, those systems accurately evaluate the gathered data (i.e. on the conditions of crops, soil and air) to address farm-related issues and make better farmrelated decisions. FMSs includes inventory management software, farm labor management and business activities management (Consolo \& D'Amico, 2017). Sixth, Precision Livestock consists in real-time monitoring of productions, health and welfare of livestock and it aims at ensuring optimal yield. It ensures a better understanding livestock, from breeding patterns to genomics. The Precision livestock applications include feeding management, heat stress management, milk harvesting management, breeding management and behavior monitoring and control. Finally, Smart Greenhouses allow farmers to grow their horticulture products with minimal human intervention. 
Factors such as temperature, humidity, luminosity, and soil moisture are constantly monitored inside a greenhouse and any variation from a predetermined threshold will trigger automated actions to keep the optimal condition for plant growth.

Smart agriculture technologies are believed to have extensive benefits in agriculture, with a prospective large economic impact, since they enhance the efficiency reducing the inputs (i.e. water, fertilizer, pesticides, seeds, etc.). Several studies on 4.0 technologies have shown to significantly increase net returns (Smith et al, 2013; Shockley et al, 2012; Shockley et al, 2011). According to Schieffer and Dillon (2015), farms endowed with smart agriculture technologies have the chance to reduce their environmental impacts, and to improve productivity and profits at once. In fact, the wider amount of data made available thanks to 4.0 technologies could enable farmers to generate more production with fewer inputs (Sustainable America, 2012). Smart agriculture would make farms' production systems more efficient and resilient, by enabling producers to increase soil yield, to detect crop diseases earlier, to reduce water and other inputs wastage, to monitor and control in-farm machines and equipment and to provide new inputs to management decision making. Potentially, those digital technologies would enable farmers to achieve a quantum leap forward in their operational and financial performance, by increasing the overall profitability by $\$ 55$ to $\$ 110$ per acre (Accenture, 2017). On average, a tractor for smart agriculture costs $20-30 \%$ more than a traditional one, and the cost per hectares can vary widely according to the type of 4.0 technology (Jobanputra, 2017; Impey, 2017; Bartolini 2017). However, if fully exploited, the additional cost would pay off after two or three harvests (Oldani, 2018).

\subsection{Sample}

We developed a survey questionnaire and distributed it to farm owners/managers in Italy. We collected data between March and June 2018. Italian farms present a strong variability in terms of distribution of the agricultural firms and their digitalization levels.

The research sample included 96 Italian farms (Figure 2 describes their geographical distribution). The respondents to our survey were located mostly in the Northern (48\%) and Central (35\%) regions of Italy, and only a minority (17\%) in the South. While this distribution might seem in contrast with the spatial distribution of agricultural firms in Italy (Italian Institute of Statistics, ISTAT Census of Agricultural firms, 2010), which appear inversely concentrated (54\% in the Southern, $26 \%$ in the Central and $20 \%$ in the Northern regions) it is not at all surprising, given that the process of digitalization of agricultural firms in Italy sees firms in the north leading at a 4\% rate of digitalization, while southern regions limited to $1.3 \%$ (ISTAT, 2017). To provide an illustrative figure, nationally, only $1,2 \%$ of the agricultural firms' management uses regularly the internet, for two main reasons: the average age of CEOs (around 55) and the digital divide caused by the lack of digital infrastructures and services.

In terms of size, only $2.2 \%$ of firms in the sample had more than 50 employees, the vast majority of farms had less than $10(88.2 \%)$, and $9.7 \%$ had between 10 and 50 .

The farms in the research sample exhibited significant variations both in the number of hectares and in the type of agricultural activity. In terms of extension, about $39.8 \%$ of surveyed farms were in the range 10.1-50 hectares, $22 \%$ of farms were in the range 5.110 hectares, $14 \%$ had agricultural land between 2.1 and 5 hectares, and $12.9 \%$ had more than 100 hectares. Finally, very few farms had an area smaller than 2 hectares $(6.5 \%)$ and 
even fewer are very large, between 50.1 and 100 hectares (5.3\%). As far as agricultural activity, about $44 \%$ of the surveyed farmers had a vineyard, whereas $34.1 \%$ had an orchard. The farms that cultivated horticulture products or legumes were about $29.7 \%$, whereas those that cultivated cereals (grain, rice, etc.) were $23.1 \%$. Similarly, $24.2 \%$ of the total farms reported to be involved in grazing and livestock activities. Olive groves accounted for about $22 \%$ of the total farms.

Regarding the farms' adopted technological innovations, software for farm management, data analytics and forecast were the most widely available (26.4\%). Smart irrigation systems and soil, plant, and crop monitoring systems accounted respectively for $11 \%$ and $8.8 \%$. Only $4.4 \%$ of surveyed farms had precision livestock systems, whereas higher percentages were observed for comprehensive systems of Smart Agriculture (8.8\%). Moreover, only $1.1 \%$ of farms adopted drones or robotics in their farm, and the same percentage of farms had invested in smart greenhouses. Conversely, a large number of farms (59.3\%) followed more traditional cultivation systems and did not use any of the 4.0 technologies.

\subsection{Measures}

In this research, all variables are self-reported by farm owners/managers. In the next sections, we provide a description of the constructs, and their reliability index.

\subsubsection{Dependent Variable.}

The dependent variable of this analysis is the decision to invest in 4.0 technologies (Lambert, Paudel \& Larson, 2015; Tey \& Brindal, 2012). We consider all the types of technologies included in smart agriculture, grouped by application (XLabs, 2017): (i) Smart irrigation and input delivery; (ii) Agriculture drones or Unmanned Aerial Vehicles (UAVs);(iii) Soil and plants monitoring systems; (iv) Yield Monitoring Systems; (v) Farm Management Software (FMSs) and Predictive Data Analytics; (vi) Precision livestock systems, (vii) Smart greenhouses.

Data regarding the investment decisions was gathered according to the type of investment in smart agriculture solutions. We constructed an indicator (similarly to Adrian et al, 2005 and Castle et al., 2016) based on the complexity and cost of each technology. We assigned each technology a value in the range from 0 to 2 . Farms with traditional agriculture or livestock systems were assigned 0 points, software 1 point, whereas all the other technologies were given 2 points. The dependent variable index includes the total number of technologies adopted by the farm, and ranges in value from 0 to 11 , with 0 meaning that the farmer currently uses no smart agriculture technologies, and 11 if the SME uses all of the technologies included in the study.

\subsubsection{Independent Variables}

To find out which variables could be included as possible predictors of the allocation of investment into 4.0 technological innovations we considered that, given characteristics of SMEs, the strategic action of a firm could depend on how managers/owners become aware and interpret change and translate their views into strategic choice (Daft \& Weick, 1984). We also took into account that firm successfully respond to a new technological opportunity when managerial cognition, organizational capability and environmental incentives are aligned toward the new opportunity (Kaplan, 2008). Therefore, the underlying assumption to design the scale was that the managerial cognition, 
organizational capabilities, and environmental incentives were meaningful variables to take into account. Yet these links have yet to be systematically explored altogether in the literature (McGee, 2005) and applied to the technology adoption.

In order to identify specific constructs to uncover managerial cognition, organizational capabilities and environmental incentives, we started interviewing CEOs, managers and owners of SMEs in agri-food sector. In particular, we collected their opinion on possible drivers of a new technology adoption in term of factors stimulating their attention for the investment, specific organizational capabilities supporting the decision to invest, and peculiar environmental characteristics incentivizing the adoption of a new technology. Three major components addressing respectively basic elements in the SMEs owners/managers' cognition, organizational capabilities and environmental incentives were thus characterized as shaping firm strategy during the adoption of a digital technology. Cognitive variables refer to the elements attracting managerial attention towards the investment and revealing the perceived opportunity behind the adoption of new technology. Managerial capabilities variables are mostly related to the organizational skills and knowledge relevant for taking the decision to adopt. Environmental variables refer to opportunities a SME can seize from its environment along the technology adoption. Overall, 23 relevant items were identified based both on the interviews and the literature review and applied in the exploratory survey. These items were divided into three categories: managerial capabilities, managerial cognition and managerial perception of the external environment (Table 1).

The responses were organized into a 5-point Likert scale (where 1= "totally disagree" and 5="totally agree"). As preliminary step, we performed an exploratory factor analysis (EFA) for all items, so as to highlight the emergent latent constructs of first and second order. Given the small sample size and the exploratory nature of the questions, we took several precautions to prevent sample size and untested items from affecting the reliability of the hypothesized model. To that end, we consider only those exploratory factors that reach a cumulative explained variance of at least $60 \%$ (MacCallum, Widaman, Zhang, \& Hong, 1999), and for the composition of factors only those that had a factor loading greater than .60 (Guadagnoli \& Velicer, 1988, p.274; Osborne \& Costello 2009). According to these authors, we can claim that the small sample size does not limit the analysis. Afterwards, we calculated Cronbach's Alpha $(\alpha)$. We accepted the result as a satisfactory outcome for all the variables based on the number of items, item intercorrelations, and dimensionality, as suggested by Cortina (1993; see also for a critic of the a-critic use of Cronbach' Alpha; Schmitt, 1996; Lance, Butt \& Michels, 2006). Table 2 reports the results of the EFA based on Principal Component Analysis and Varimax rotation indicating the latent factors obtained. Items that did not meet the above-mentioned rules were not included in the calculation of the latent factors.

\subsubsection{Control variables}

Following previous studies (e.g., Castle et al., 2016; Paxton et al., 2010) we controlled for several variables potentially influencing the adoption of 4.0 technologies for smart agriculture.

We chose as control variables both farm size by number of employees, and the number of years the surveyed farmer has been in the role of owner, CEO or manager. The number of employees represents a good proxy of the resources that a farm can dedicate to investments in state-of-the-art production systems, thus their effect should be isolated 
when analyzing the statistical relationship between the adoption of smart agriculture technologies and the predictive variables. Therefore, we created a categorical variable ranging from a baseline value of 1 for enterprises with less than 10 employees to 3 for farms that have more than 50 .

Additionally, since the manager/owner interpretation of technological issues might result from accumulations through a variety of experiences, as well as education or jobs (Kaplan, 2008), we have controlled for the decision-makers' experience and education. Regarding CEO, manager or owner experience, we created a categorical variable ranging from a baseline value of 1 for decision-makers having between two and five years of experience and a maximum value of 6 for decision-makers with more than fifty years of experience. We then created a categorical variable regarding the level of education of the farm's decision-maker, ranging from primary/secondary education as baseline category to $\mathrm{PhD} /$ post-graduate level.

Finally land size could also affect the adoption of advanced farming technologies. We associated the value of 1 to farms of less than two hectares (our reference point), and the maximum value of 6 to farms over one hundred hectares.

\subsection{Statistical Analysis}

We used Stata software to run our statistical analysis. In particular, we used a specific type of Poisson Regression, the Negative Binomial Regression, to adjust for overdispersion, because the conditional variance of our dependent variable is higher than the conditional mean. The choice of a count data regression model relies on the fact that our dependent variable is defined on a discrete and non-negative level (Greene, 2000, p. 886). Because our methodology was a maximum likelihood one, no statistics such as variance inflation factors (VIFs) were available. Additionally, our results remained quite stable across a number of analyses, and this stability, coupled with the low correlations among the independent variables, led us to conclude that multicollinearity was not a problem. Finally, our approach is also consistent with previous studies such as Castle and colleagues (2016) and Paxton and colleagues (2010).

\section{Results}

Descriptive statistics including means and standard deviations, are presented in Table 3, and inter-correlations are reported in Table 4. The results of the Negative Binomial Regression models are reported in Table 5. Model 5 shows the results of the full model were all the hypotheses were tested together. Model 1 shows the result of our first hypothesis (HP1) which speculates about a positive relationship between managerial capabilities and the adoption of advanced technological innovations. HP1 is confirmed since the coefficient for our latent construct "Evidence Based Knowledge", the knowledge and evidence collected by the SME's decision-maker, is positive, and highly significant $(\beta=0.721, \mathrm{p}<0.001)$. This model significantly differs from the baseline model (Model 1) LR chi2 $(1)=13.96$ and $\mathrm{p}<0.001$.

HP2 predicts that the allocation of investment into 4.0 technological innovations is positively associated with the managerial cognition related to the perception of opportunities that the technology can provide. Model 3 shows the coefficients for 
"Perception of technological usefulness", Economic concerns", and "Trade-off costbenefit" that represent proxies for the perception of opportunity. More specifically, responding to the need to better understand why decision-makers respond to changes in their perception of opportunities, we have accounted within the related construct three distinct factors. First, in line with Davis (1989), we found that perceived usefulness is a pivotal element of this construct, as demonstrated by its strong significance in the analysis. In particular, perception of the technological usefulness was positive and significant $(\beta=0.309, p<0.05)$. In line with Davis (1989), we have also focused on the cost-benefit paradigm. Previous studies (e.g. Davis 1989) have in fact showed that the cost-benefit trade-off relates to perceived usefulness and ease of use, and thus affects the decision-making strategies. Extant research has debated the efficacy of cost-benefit subjective or objective measures (see Venkatesh, Morris, Davis \& Davis, 2003), and while we followed the suggestion to focus on the decision-maker's perceived costs and benefits, we did not find a significant effect of this variable within our study. Finally, we have included in the analysis the effect of economic concerns. In line with previous literature (see Suzuki et al., 2002), we didn't find significance for this factor within the analysis. Thus, we partially confirmed our second hypothesis. However, this model does not differ from the baseline LR chi2(3) $=5.80$ and $p=0.12$.

HP3 states a positive relationship between the managerial perception of the external environment and the adoption of advanced agricultural technologies. Model 4 shows the results related to the perception of supporting "Business Services", "Contextual Factors" and "Infrastructure Availability". Previous literature (Suzuki et al. 2002; Venkatesh et al., 2003), has built on such indicators to verify existent relation to technological adoption. While the role of supporting business services, either in the form of professional services or institutional support, has proved a consistently positive relation to technology adoption, we were expecting controversial results, which are confirmed by the limited significance, from the component related to contextual factors. This might be due to the fact that within the contextual latent construct we also account for social influence. Controversial evidence was found on the latter by previous research (see Venkatesh et al., 2003 for a review). Finally, we tested the effect of the availability of an infrastructure carrying connectivity and convenience of communication, which does not appear to be statistically significant within the study. Among these factors both the coefficients related to the satisfaction with the business services together with the perception of the availability of cheap and easy communication, related to the contextual factors, and more general perception of the environment related to financial support and competition were positive and significant $(\beta=0.553, \mathrm{p}<0.001 ; \beta=0.429, \mathrm{p}<0.05)$. This partially confirms our HP3. Additionally, this model is significantly different from the baseline model LR chi2(3) $=13.23$ and $\mathrm{p}<0.01$.

Finally, when we confront the different set of predictions related to managerial capabilities, managerial perceptions of opportunity and of the external environment related to the explanatory variables emerged from our EFA, we see that the pattern and directions of the results is still confirmed (Model 5). Interestingly enough, we found that "Evidence Based Knowledge" is still positive, and highly significant $(\beta=0.679, p<$ 0.01 ) while the belief about the usefulness of the technologies for the agriculture is still positive but its significance was reduced at a 90\% confidence interval $(\beta=0.242, \mathrm{p}=$ 0.073). Finally, "Business Service" remains positive and significant $((\beta=0.394, p<$ 
$0.01)$ while the perception of the environment related to the "Contextual Factors" turned to be insignificant $(\beta=0.242, p=0.073)$. Additionally, this model differs from the baseline model with only controls LR chi2 $(7)=25.3$ and $p<0.001$ further supported by the lower value of the Aiken Information Coefficient (i.e. AIC) comparing the two models (Model 1 AIC $=274.341$ and Model 5 AIC $=263.0397)$. Moreover, the full model (Model 5) is also significantly different from the models testing separately our hypotheses. Finally, the results remain stable even if we use different analytical strategies, such as ordered probit and logit models. Overall, these additional robustness checks boost our confidence in the stability and validity of our predictions and analysis.

\section{Discussion}

Our study contributes to explain why SMEs adopt 4.0 technologies. Relying on the interviews with SMEs' managers/owners we were able to identify the specific elements explaining the organizational capabilities, managerial cognition, and environmental incentives that affect the managerial decision to allocate investment on digital technological innovations. Thus, our study not only addresses the issue of scope limitation experienced by previous literature (such as a too strict focus on usage or success or little empirical research, often limited in scope, see Premkumar \& Roberts, 1998; Long et al., 2016; Long et al., 2017), but also allows to focus more thoroughly on the relevant specific aspects driving the decision to adopt new digital technology within SMEs. We were indeed able to account and separate the effect of single organizational, cognitive and environmental dimensions. This is an important aspect of the study, since each of these dimensions offers CEOs, managers or owners different stimuli for decision-making, embedding different endogenous or exogenous elements to the firm. This novelty element is reflected in the study design, and more specifically in the selection of the proxies used to test our Hypothesis 2 and 3. While Hypothesis 1 confirmed the importance of organizational capabilities related to the search for evidence-based knowledge by the SME's decision-maker, the constructs of perception of opportunity and supporting business environment required a more detailed analysis. They represent, indeed, multidimensional constructs, involving a variety of factors able to capture the complexity involved in the decision of adopting a new technology. Our results showed that, beyond the role of the search for evidence-based knowledge, only specific cognitive or environmental aspects are statistically related to the allocation of investment. In particular, we found that across the different factors the ones strongly associated to the adoption of new technology are the one related to attention-triggering elements, such as the perception of technological usefulness, or external pressures such as business services are found to be more relevant than economic concerns or cost-benefits beliefs. A possible explanation can be found in the fact that managerial cognition is related to environmental incentives and organizational capabilities (Kaplan, 2008) as they all affected the decisionmakers in the need to rely on their repertoires of accumulated knowledge to interpret situations and make strategic decisions (Elsbach, Barr, \& Hagardon, 2005; Kaplan, 2008). By doing so, we have been able to confirm the importance of organizational capabilities, managerial cognition and environmental incentives as we proved that all of them affect the decision to adopt a new digital technology and to identify the specific sub-dimensions that are statistically relevant for the decision of investing in new digital technology.

Our study, thus, sheds light on the role of SMEs managers' perceptions and their impact 
on strategic action. In fact, in line with the current literature that stresses the links between strategic responses and events and managerial cognition (Barr \& Huff, 1997), we focus on the managerial beliefs underlying the adoption decision, rather than on the adoption per se.

Our results direct future scholarly attention to patterns of beliefs regarding the external environment, and the relationship between beliefs and action, since strategic action will be influenced by these patterns, in either speed or content. More generally, our study suggests a more complex picture of the interplay between the above-mentioned factors that needs further investigations.

Another important aspect our study underlines is the potential interplay between managerial cognition and organizational capabilities, since our results suggest that managerial attention can partially compensate for lack of capabilities (Rosenbloom, 2000 ) by seeking new evidence-based knowledge. A manager's attention to a new technology could be a forward-looking force that drives search efforts in new arenas (Gavetti \& Levinthal, 2000). Our study shows that, while leveraging on organizational capabilities to scan the environment to seek for evidence-based knowledge, managers' build on their beliefs about the usefulness of the technology and the knowledge about the technology itself can further compensate the lack of opportunities present in the external environment in fostering the adoption of new technologies (Adrian et al., 2005). Thus, we acknowledge the pivotal role of the owner/manager within SMEs, who seeks, filters, selects and uses evidence and information simultaneously in the decision-making process. Normatively, in line with Kaplan (2008), we suggest that a major problem related to the adoption of a new digital technology may reside in the fact that decisionmakers might lack relevant knowledge, hindering thus strategic actions, and that the organizational capabilities architecture might limit the chance to act on the perceived opportunities and environmental incentives, especially when solid routines are in place. Our study also underlined the elements able to trigger managerial attention and shape the decision to invest, providing a more complete explanation of the phenomenon of technology adoption by SMEs (e.g., Johnson \& Hoopes, 2003).

\subsection{Managerial implications}

Our study offers new insights for managers and practitioners. First, we confirm that organizational routines and capabilities to collect evidence-based knowledge affect decisions of investment allocation in 4.0 technology. This is a pivotal finding in the case of SMEs, because decision-making is strongly centralized and relies in the apical actor of the organization (Stanworth \& Gray, 1992), and individual cognition may compensate for lack of resources. A straightforward implication for manufacturers of smart agriculture technologies might be to modify their communication strategies with business consumers, by building on their absorptive capacity and their accumulation of knowledge, in order to increase the responsiveness owners/managers to technical change and investment decisions.

Second, given the significant role of the owner/manager, we could not leave aside the relevance of his/her cognition in the investment allocation decision. This finding also carries relevant implications for technology suppliers, who might want to offer additional support to business customers, for example through ad-hoc training programs aimed at illustrating the latest technologies on the market, and the benefits of smart agriculture in terms of efficiency, cost savings, profitability and sustainability. Finally, 
our insight on the crucial role of supporting services in the investment allocation decision suggests that such services can provide decision-makers additional information and support in processing data to enhance the IT adoption process. Ecosystem actors, such policy-makers, but also technology suppliers or business partners, could focus on the establishment of a proper supporting business services environment.

\subsection{Limitations}

Our study presents some limitations that need to be acknowledged.

The analysis has geographical restrictions, both at cross-country and country level. First, we surveyed farm holders only in Italy. Repeating the survey in countries other than Italy could potentially reveal a different scenario in terms of the relative importance of the factors analyzed in this study. Second, Italy presents a strong variability in terms of distribution of the agricultural firms and their digitalization levels, as described in the sample section.

Additionally, our cross-sectional design prevents us to claim causal inferences. However, our analytic strategy and robustness checks give us confidence in the stability and validity of the obtained results. Future studies could adopt experimental or longitudinal design in order to address this limitation. Furthermore, the inclusion of hard data concerning the actual macroeconomic conditions of a country could reveal why some countries are more proactive in investing in digital innovations than others. Such considerations could explain why North America has been more "fertile" grounds for smart agriculture as opposed to the rest of the world, both in terms of number of hi-tech start-ups and extent of digitalized land (Roland Berger, 2015).

\section{Conclusions}

4.0 technologies for smart agriculture bring several benefits to agricultural SMEs, in terms of increased yields, reduced costs, bigger profits, more information for better decisions, and sustainability. But the penetration of such digital technologies in farms is still circumscribed and slow, despite the compelling social, environmental and sustainability challenges of the next decades.

In answer to this dilemma, we provide insights on the reasons why the adoption of 4.0 technologies within SMEs is still limited. We do not focus on adoption per se, but rather on the managerial beliefs underlying the adoption decision, such as the perception of opportunity, the active search for evidence-based knowledge, or the perception of a proper supporting external environment. These elements may trigger managerial attention and shape the response to the opportunity to adopt a new IT solution. We analyze data collected by surveying 96 Italian agricultural SMEs owners/managers, and examine the role of managerial cognition, organizational capabilities and perception in the adoption of 4.0 technologies for smart agriculture.

Our work can help hi-tech start-ups, established companies and governments in developing the right strategies and policies to spread digital innovation in the agricultural sector. Current literature still needs to understand the factors influencing the farmers' decisions to adopt Smart Solutions, and future research might indeed extend our model looking at more complex interplay between our variables or identifying new factors that will provide additional insights. 


\section{References}

Acar, E., Kocak, I., Sey, Y., \& Arditi, D. (2005). Use of information and communication technologies by small and medium-sized enterprises (SMEs) in building construction. Construction Management and Economics, 23(7), 713-722.

Accenture. (2017). Digital Agriculture: Improving Profitability. Retrieved from https://www.accenture.com/_acnmedia/Accenture/ConversionAssets/DotCom/Documents/Global/PDF/Digital 3/Accenture-Digital-AgriculturePoint-of-View.pdf

Adrian, A. M., Norwood, S. H., \& Mask, P. L. (2005). Producers' perceptions and attitudes toward precision agriculture technologies. Computers and Electronics in Agriculture, 48, 256-271.

Anderson, C. (2014). Agricultural Drones. Relatively cheap drones with advanced sensors and imaging capabilities are giving farmers new ways to increase yields and reduce crop damage. MIT Technology Review. Retrieved at: https://www.technologyreview.com/s/526491/agricultural-drones/

Atherton, A., \& Hannon, P. D. (2000). Innovation processes and the small business: a conceptual analysis. International journal of business performance management, 2(4), 276- 292.

Barnett, W. P. (1990). The organizational ecology of a technological system. Administrative Science Quarterly, 35, 31-60.

Barr, P. S., \& Huff, A. S. (1997). Seeing isn't Believing: Understanding Diversity in the Timing of Strategic Response. Journal of Management Studies, 34(3), 337-370.

Bartolini, R. (2017, March 17). Agricoltura di precisione: quanto costa e quanto possiamo risparmiare evitando gli sprechi. Retrieved from: http://www.ilnuovoagricoltore.it/agricoltura-di-precisione-quanto-costa-e-quantopossiamo-risparmiare-evitando-gli-sprechi/

Blili, S., \& Raymond, L. (1993). Information technology: Threats and opportunities for small and medium-sized enterprises. International Journal of Information Management: The Journal for Information Professionals, 13(6), 439-448.

Bourgeois, L. J. (1980). Strategy and Environment: A Conceptual Integration. Academy of Management Review, 5(1), 25-39.

Bull, C. (2003). Strategic issues in customer relationship management (CRM) implementation. Business process management Journal, 9(5), 592-602.

Carson, D., \& Gilmore, A. (2000). Marketing at the interface: not 'what 'but 'how'. Journal of marketing theory and practice, 8(2), 1-7.

Castle, M. H., Lubben, B. D. \& Luck, J.D., (2016). Factors Influencing the Adoption of Precision Agriculture Technologies by Nebraska Producers. University of Nebraska Presentations, Working Papers, and Gray Literature: Agricultural Economics. 49, Retrieved at: http://digitalcommons.unl.edu/ageconworkpap/49

Chell, E., \& Baines, S. (2000). Networking, entrepreneurship and microbusiness behaviour. Entrepreneurship \& regional development, 12(3), 195-215.

Cho, T. S., \& Hambrick, D. C. (2006). Attention as the mediator between top management team characteristics and strategic change: The case of airline deregulation. Organization Science, 17(4), 453-469.

Cohen, W. M., \& Levinthal, D. A. (1990). Absorptive Capacity: A New Perspective on Learning and Innovation. Administrative Science Quarterly, 35, 128-152.

Consolo, V., \& D'Amico, V. (2017). Smart Agriculture: il Terreno Fertile per il $5 G$. 
Retrieved from: http://www.telecomitalia.com/tit/it/notiziariotecnico/edizioni2017/n-2-2017/capitolo-6.html

Corbett, A. C. (2005). Experiential learning within the process of opportunity identification and exploitation. Entrepreneurship: Theory \& Practice, 29(4), 473-491.

Cortina, J. M. (1993). What is coefficient alpha? An examination of theory and applications. Journal of Applied Psychology, 78(1), 98-104.

Daft, R. L., \& Weick, K. E. (1984). Toward a Model of Organizations as Interpretation Systems. Academy of Management Review, 9, 284-295.

Davis, F. D. (1989). Perceived usefulness, perceived ease of use, and user acceptance of information technology. MIS quarterly, 319-340.

Deloitte. (2016). From Agriculture to AgTech: An industry transformed beyond molecules and chemicals. Retrieved from https://www.gita.org.in/Attachments/Reports/DeloitteTranformation-from-Agriculture-to-AgTech.pdf

De Clerqc, M., Vats, A., \& Biel, A. (2018). Agriculture 4.0: The Future of Farming Technology. World Government Summit and Oliver Wyman. Retrieved from: https://www.oliverwyman.com/our-expertise/insights/2018/feb/agriculture-4-0--thefuture-of-farming-technology.html

DeLone, W. H. (1988). Determinants of success for computer usage in small business. Mis Quarterly, 51-61.

Desai, C., Wright, G., \& Fletcher, K. (1998). Barriers to successful implementation of database marketing: a cross-industry study. International Journal of Information Management, 18(4), 265-276.

Dutton, J. E., \& Jackson, S. E. (1987). Categorizing Strategic Issues: Links to Organizational Action. Academy of Management Review, 12(1).

Dutton, J. E., Fahey, L., \& Narayanan, V. K. (1983). Toward Understanding Strategic Issue Diagnosis. Strategic Management Journal, 4(4), 307-323.

Elsbach, K. D., Barr, P. S., \& Hargadon, A. B. (2005). Identifying situated cognition in organizations. Organization Science, 16(4), 422-433.

European Commission. (2015). Glossary of terms related to the Common Agricultural Policy. Retrieved from Agriculture and Rural Development: https://ec.europa.eu/agriculture/glossary en

FAO (2017). Information and Communication Technology (ICT) in Agriculture. Retrieved from www.fao.org/3/a-i7961e.pdf

Fink, D. (1998). Guidelines for the successful adoption of information technology in small and medium enterprises. International journal of information management, 18(4), 243-253.

Fiol, M., \& O'Connor, E. J. (2003). Waking up! Mindfulness in the Face of Bandwagons Author(s): C. Academy of Management Review, 28(1).

Fiske, S. T., \& Taylor, S. E. (1991). Social cognition. McGraw-Hill series in social psychology. New York, NY, England: Mcgraw-Hill Book Company .

Fletcher, K., \& Wright, G. (1995). Organizational, strategic and technical barriers to successful implementation of database marketing. International Journal of Information Management, 15(2), 115-126.

FullerLove, N. (2006). Management development in small firms. International Journal of Management Reviews, 8(3), 175-190.

Gable, G. G. (1991). Consultant engagement for computer system selection: a pro-active client role in small enterprises. Information \& Management, 20(2), 83-93.

Gavetti, G., \& Levinthal, D. (2000). Looking forward and looking backward: Cognitive 
and experiential search. Administrative science quarterly, 45(1), 113-137.

Greene, W. H. (2000). Econometric analysis (4th ed.). Upper Saddle River, NJ: Prentice Hall.

Griffith, C., Heydon, G., Lamb, D., Lefort, L., \& Taylor, K. (2013). Smart Farming: leveraging the impact of broadband and the digital economy. CSIRO and University of New England. Retrieved from: https://publications.csiro.au/rpr/download?pid=csiro:EP137659\&dsid=DS2.

Guadagnoli, E., \& Velicer, W. F. (1988). Relation to sample size to the stability of component patterns. Psychological bulletin, 103(2), 265.

Hambrick, D. C. (1981). Strategic awareness within top management teams. Strategic Management Journal, 2(3), 263-279.

Hovav, A., Patnayakuni, R., \& Schuff, D. (2004). A model of Internet standards adoption: the case of IPv6. Information Systems Journal, 14(3), 265-294.

Hsu, W. T., Chen, H. L., \& Cheng, C. Y. (2013). Internationalization and firm performance of SMEs: The moderating effects of CEO attributes. Journal of World Business, 48(1), 1-12.

Huff, A. S. (1990). Mapping strategic thought. John Wiley \& Sons.

Impey, L. (2017, September 12). Precision farming trial to reveal true cost of technology. Retrieved from: https://www.futurefarming.com/Toolsdata/Articles/2017/9/Precision-farming-trial-to-reveal-true-cost-of-technology$\underline{1582 \mathrm{WP} /}$

ISTAT. (2010). Census of agricoltural firms. Retrieved from https://www.istat.it/it/files/2011/03/142512 Vol_VI Cens Agricoltura INT_CD_1 Trimboxes ipp.pdf

ISTAT. (2017). Annuario Statistico Italiano. Retrieved from https://www.istat.it/it/files/2017/12/Asi-2017.pdf

Jauch, L. R., \& Kraft, K. L. (1986). Strategic Management of Uncertainty. Academy of Management Review, 11(4), 777-790.

Jobanputra, A. (2017, August 22). How much will it cost to make a smart farming solution? Retrieved from Quora.com: https://www.quora.com/How-much-will-itcost-to-make-a-smart-farming-solution

Johnson, D. R., \& Hoopes, D. G. (2003). Managerial cognition, sunk costs, and the evolution of industry structure. Strategic Management Journal, 24(10), 1057-1098.

Jones, O., \& Macpherson, A. (2006). Inter-organizational learning and strategic renewal in SMEs: extending the. Long Range Planning, 39(2), 155-75.

Kaplan, A., \& Haenlein, M. (2019). Siri, Siri, in my hand: Who's the fairest in the land? On the interpretations, illustrations, and implications of artificial intelligence. Business Horizons, 62(1), 15-25.

Kaplan, S. (2008). Cognition, capabilities, and incentives: Assessing firm response to the fiber-optic revolution. Academy of Management Journal, 51(4), 672-695.

Khaitan, S. K., \& McCalley, J. D. (2015). Design techniques and applications of cyberphysical systems: A survey. IEEE Systems Journal, 9(2), 350-365.

Kotey, B., \& Folker, C. (2007). Employee Training in SMEs: Effect of Size and Firm Type - Family and Nonfamily. Journal of Small Business Management, 45(2), 214238.

Kranz, M. (2017). Success with the Internet of Things Requires More Than Chasing the Cool Factor. Harvard Business Review. Retrieved from: https://hbr.org/2017/08/success-with-the-internet-of-things-requires-more-than- 
chasing-the-cool-factor

Lambert, D. M., Paudel, K. P., \& Larson, J. A. (2015). Bundled adoption of precision agriculture technologies by cotton producers. Journal of agricultural and resource economics, 325-345.

Lance, C. E., Butt, M. M., \& Michels, L. C. (2006). The Sources of Four Commonly Reported Cutoff Criteria. What Did They Really Say? Organizational Research Methods, 9(2), 202-220.

Larson, J. A., Roberts, R. K., English, B. C., Larkin, S. L., Marra, M. C., Martin, S. W., \& Reeves, J. M. (2008). Factors Influencing Adoption of Remotely Sensed Imagery for Site- Specific Management in Cotton Production. Precision Agriculture, 9, 195208.

Lefebvre, L. A., Mason, R., \& Lefebvre, E. (1997). The influence prism in SMEs: The power of CEOs' perceptions on technology policy and its organizational impacts. Management science, 43(6), 856-878.

Leonard-Barton, D. (1992). Core Capabilities and Core Rigidities: A Paradox in Managing New Product. Strategic Management Journal, 13, 111-125.

Levinthal, D. A., \& March, J. G. (1993). The Myopia of Learning. Strategic Management Journal, 4(S2), 95-112.

Liao, J., Welsch, H., \& Stoica, M. (2003). Organizational absorptive capacity and responsiveness: an empirical investigation of growth-oriented SMEs. Entrepreneurship Theory and practice, 28(1), 63-85.

Long, T. B., Blok, V., \& Coninx, I. (2016). Barriers to the adoption and diffusion of technological innovations for climate-smart agriculture in Europe: evidence from the Netherlands, France, Switzerland and Italy. Journal of Cleaner Production, 112, 9-21.

Long, T. B., Blok, V., \& Poldner, K. (2017). Business models for maximising the diffusion of technological innovations for climate-smart agriculture. International food and agribusiness management review, 20(1), 5-23.

MacCallum, R. C., Widaman, K. F., Zhang, S., \& Hong, S. (1999). Sample size in factor analysis. Psychological methods, 4(1).

Maddalena, E. (2015). Smart Farm: di cosa si tratta e qual è il ruolo dell'IoE? Retrieved from Tech Economy: Retrieved at: http://www.techeconomy.it/2015/04/23/smartfarm-si-tratta- qual-ruolo-dellioe/

McAfee, A., \& Brynjolfsson, E. (2012). Big data: the management revolution. Harvard business review, 90(10), 60-68.

McGee, M. (2005). Self-help, Inc.: Makeover culture in American life. Oxford University Press on Demand.

Mitchell, W., \& Singh, K. (1992). Incumbents use of preentry alliances before expansion into new technical subfields of an industry. Journal of Economic Behavior \& Organization, 18(3), 347-372.

Nadkarni, S., \& Barr, P. S. (2008). Environmental Context, Managerial Cognition, and Strategic Action: An Integrated View. Strategic Management Journal, 29, 1395-1427.

Nelson, R. R., \& Winter, S. G. (1982). An Evolutionary Theory of Economic Change. Cambridge, Massachusetts: The Belknap Press of Harvard University Press.

Ocasio, W. (1997). Towards an attention-based view of the firm. Strategic Management Journal, 18(S1), 198-206.

Oldani, R. (2018). Trattori hi-tech e droni nei campi. Focus Extra, 24-29.

Osborne, J. W., \& Costello, A. B. (2009). Best practices in exploratory factor analysis: Four recommendations for getting the most from your analysis. Pan-Pacific 
Management Review, 12(2), 131-146.

Paxton, K. W., Mishra, A. K., Chintawar, S., Larson, J. A., Roberts, R. K., English, B. C., \& Lambert, D. M. (2010). Precision Agriculture Technology Adoption for Cotton Production. Southern Agricultural Economics Association.

Powell, T. C., \& Dent-Micallef, A. (1997). Information technology as competitive advantage: The role of human, business, and technology resources. Strategic management journal, 18(5), 375-405.

Premkumar, G. (2003). A meta-analysis of research on information technology implementation in small business. Journal of organizational computing and electronic commerce, 13(2), 91-121.

Premkumar, G. P., Ramamurthy, K., \& Nilakanta, S. (1994). Implementation of Electronic Data Interchange: An Innovation Diffusion Perspective. Journal of Management Information Systems, 11(2), 157-186.

Premkumar, G., \& Roberts, M. (1998). Adoption of new information technologies in rural small businesses. Omega, 27(4), 467-484.

Premkumar, G., Ramamurthy, K., \& Crum, M. (1997). Determinants of EDI adoption in the transportation industry. European Journal of Information Systems, 6(2), 107-121.

Riemenschneider, C. K., Harrison, D. A., \& Mykytyn Jr, P. P. (2003). Understanding IT adoption decisions in small business: integrating current theories. Information \& management, 40(4), 269-285.

Rogers, E. (1995). Diffusion of Innovations (4th ed.). New York, NY, USA: Free Press.

Roland Berger. (2015). Business opportunities in Precision Farming: will big data feed the world in the future? Retrieved from: https://www.rolandberger.com/sv/Publications/Business-opportunities-in-PrecisionFarming.html

Rosenbloom, R. S. (2000). Leadership, capabilities, and technological change: The transformation of NCR in the electronic era. Strategic Management Journal, 21(10-11), 1083-1103.

Rosenkopf, L., \& Nerkar, A. (2001). Beyond Local Search: Boundary-Spanning, Exploration, and Impact in the Optical Disk Industry. Strategic Management Journal, 22(4), 287-306.

Ruef, M. (2005). Origins of organizations: The entrepreneurial process. (Review). Research in the Sociology, 15, 63-100.

Schieffer, J., \& Dillon, C. (2015). The Economic and Environmental Impacts of Precision Agriculture and Interaction with Agro-Environmental Policy.". Precision Agriculture, 16, pp. 46-61.

Schmitt, N. (1996). Uses and Abuses of Coefficient Alpha. Psychological Assessment, 8(4), 350-353.

Shane, S., \& Venkataraman, S. (2000). The promise of entrepreneurship as a field of research. Academy of Management Review, 25(1), 217-226.

Sharma, S., \& Rai, A. (2003). An assessment of the relationship between ISD leadership characteristics and IS innovation adoption in organizations. Information \& Management, 40(5), 391-401.

Shin, I. (2006). Adoption of enterprise application software and firm performance. Small Business Economics, 26(3), 241-256.

Shockley, J. M., Dillon, C. R., \& Stombaugh, T. S. (2011). A Whole Farm Analysis of the Influence of Auto-Steer Navigation on Net Returns, Risk, and Production Practices. Journal of Agricultural and Applied Economics, 43(1), pp. 57-75. 
Shockley, J., Dillon, C. R., Stombaugh, T., \& Shearer, S. (2012). Whole Farm Analysis of Automatic Section Control for Agricultural Machinery. Precision Agriculture, 13, pp. 411-420.

Simmie, J. (2002). Knowledge spillovers and reasons for the concentration of innovative SMEs. Urban Studies, 39(5-6), 885-902.

Smith, C. M., Dhuyvetter, K. C., Kastens, T. L., Kastens, D. L., \& Smith, L. M. (2013). Economics of Precision Agricultural Technologies Across the Great Plains. Journal of the ASFMRA.

Soliman, K. S., \& Janz, B. D. (2004). An exploratory study to identify the critical factors affecting the decision to establish Internet-based interorganizational information systems. Information \& Management, 41(6), 697-706.

Sorensen, J. B., \& Stuart, T. E. (2000). Aging, Obsolescence, and Organizational Innovation. Administrative Science Quarterly, 45(1), 81-112.

Southern, A., \& Tilley, F. (2000). Small firms and information and communication technologies (ICTs): toward a typology of ICTs usage. New technology, work and employment, 15(2), 138-154.

Stanworth, J., \& Gray, C. (1992). Enterprise education: Action-Based research with training policy implications. International Small Business Journal, 10(2), 11-23.

Sultan, N. A. (2011). Reaching for the "cloud": How SMEs can manage. International journal of information management, 31(3), 272-278.

Sustainable America. (2012, November 5). Precision Agriculture: Increasing Food Availability Through Efficiency in America's Food Systems.

Suzuki, K. I., Kim, S. H., \& Bae, Z. T. (2002). Entrepreneurship in Japan and Silicon Valley: a comparative study. Technovation, 22(10), 595-606.

Swanson, E. B., \& Ramiller, N. C. (1997). The organizing vision in information systems innovation. Organization science, 8(5), 458-474.

Swanson, E. B., \& Wang, P. (2005). Knowing why and how to innovate with packaged business software. Journal of Information Technology, 20(1), 20-31.

Teo, T. S., \& Pian, Y. (2003). A contingency perspective on Internet adoption and competitive advantage. European Journal of Information Systems, 12(2), 78-92.

Tey, Y. S., \& Brindal, M. (2012). Factors influencing the adoption of precision agricultural technologies: a review for policy implications. Precision agriculture, 13(6), 713-730.

Thomas, J. B., Clark, S. M., \& Gioia, D. A. (1993). Strategic Sensemaking and Organizational Performance: Linkages among Scanning, Interpretation, Action, and Outcomes. Academy of Management Journal, 36(2), 239-270.

Tihanyi, L., \& Thomas, W. B. (2005). Information-processing demands and the multinational enterprise: A comparison of foreign and domestic earnings estimates. Journal of Business Research, 58(3), 285-292.

Van Es, H., \& Woodard, J. (2017). Innovation in Agriculture and Food Systems in the Digital Age. The global innovation index, 99.

Venkatesh, V., Morris, M. G., Davis, G. B., \& Davis, F. D. (2003). User acceptance of information technology: Toward a unified view. MIS quarterly, 425-478.

Walsh, J. P. (1995). Managerial and organizational cognition: Notes from a trip down memory lane. Organization science, 6(3), 280-321.

Walton, J. C., Larson, J. A., Roberts, R. K., Lambert, D. M., English, B. C., Larkin, S. L., \& Reeves, J. M. (2010). Factors Influencing Farmer Adoption of Portable Computers for Site- Specific Management: A Case Study for Cotton Production. Journal of 
Agricultural and Applied Economics, 42(2), 193-20

Warren, D. (1978). Commercial Liberation. Journal of Communication, 28(1), 169-173.

Weick, K. E. (1995). Sensemaking in Organizations. London: SAGE.

Wheeler, S. A. (2008). The barriers to further adoption of organic farming and genetic engineering in Australia: views of agricultural professionals and their information sources. Renewable Agriculture and Food Systems, 23(2), 161-170.

Xlabs (2017) The connected farm. A smart agriculture market assessment. Huawei Xlabs Wireless Report. Retrieved online on https://www.huawei.com/uk/industry-insights.

Young, D., Carr, H. H., \& Rainer, R. K. (1999). Strategic implications of electronic linkages. Information Systems Management, 16, 32-39 
8. Figures and tables

FIGURE 1

Theoretical model

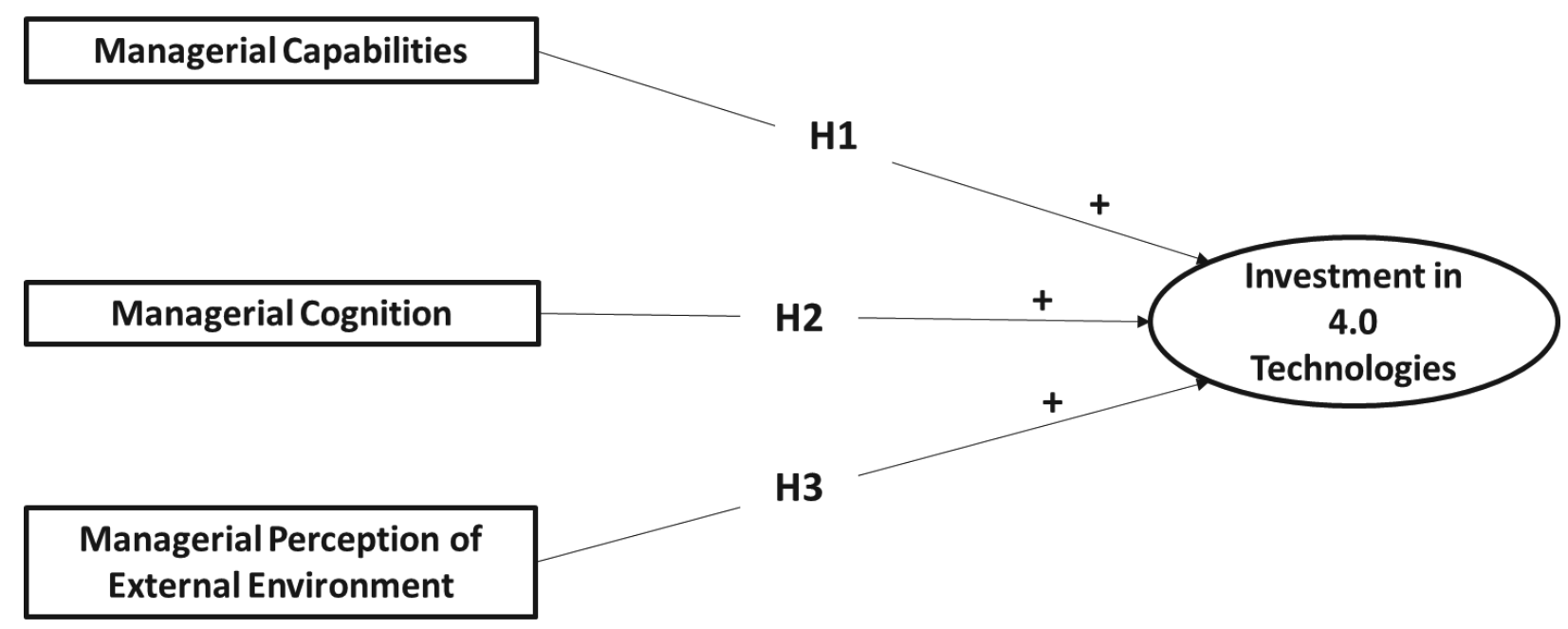


FIGURE 2

Geographical distribution of Interviewed AMEs



24 
TABLE 1

Items identified and categorized into Managerial Capabilities, Managerial Cognition and

Managerial Perception of the External Environment

\begin{tabular}{|c|c|}
\hline Macro Component & Items \\
\hline \multirow{5}{*}{ Managerial Capabilities } & I have employees dedicated to the management and/or research of new digital technology for my farm \\
\hline & How often I look for information about agricultural digital technologies on Internet \\
\hline & How often I go to events on digital technology for agriculture \\
\hline & How often I read articles about digital technology for agriculture \\
\hline & How often I contact/meet digital technology providers \\
\hline \multirow[t]{6}{*}{ Managerial Cognition } & Digital technology is very useful to agriculture/livestock \\
\hline & I believe that digital technology 4.0 brings/would bring real benefits to my farm (higher revenues and/or lower costs) \\
\hline & I don't want digital technology in my farm because I believe agriculture should be more traditional and "natural" \\
\hline & I have difficulties in accessing financing (from banks or private investors) \\
\hline & I believe that digital technologies 4.0 are too expensive \\
\hline & I believe that the cost of digital technologies does not offset their benefits (higher revenues and/or lower costs) \\
\hline \multirow{12}{*}{$\begin{array}{l}\text { Managerial Perception of } \\
\text { External Environment }\end{array}$} & I would invest more in digital technologies if financial support from the government was higher (subsides, lower taxes) \\
\hline & I would invest more in digital technologies if access to digital consulting services was more convenient (price and/or quality) \\
\hline & I would invest more in digital technologies if support from the government was higher (advisory and consulting services) \\
\hline & If I had higher financial availability, I would invest more in digital technology for my farm \\
\hline & In the place where I live, investing in new technological innovations is an element of appreciation and respect \\
\hline & I know many competitors that are investing in digital technology for their farm \\
\hline & I would invest more in digital technology if connectivity was more reliable \\
\hline & I would invest more in digital technologies if the quality/convenience of communication services was higher \\
\hline & I don't have connectivity problems in my farm (phone, Internet) \\
\hline & In my country the government provides incentives for investments in digital technology for agriculture (subsides, lower taxes, other services) \\
\hline & I believe that accessing communication services (phone, Internet) is easy and cheap \\
\hline & I am fully satisfied with the consulting services (IT and digital) available to my enterprise \\
\hline
\end{tabular}


TABLE 2

EFA based on Principal Component Analysis and Varimax rotation indicating the latent factors obtained

\begin{tabular}{|c|c|c|c|}
\hline & Component 1 & Component 2 & Component 3 \\
\hline & Contextual Factors & $\begin{array}{l}\text { Infrastructure } \\
\text { Availability }\end{array}$ & $\begin{array}{l}\text { Evidence Based } \\
\text { Knowledge }\end{array}$ \\
\hline & $a=0,77$ & $a=0,90$ & $a=0,87$ \\
\hline $\begin{array}{l}\text { I would invest more in digital } \\
\text { technologies if financial support } \\
\text { from the government was higher } \\
\text { (subsides, lower taxes) }\end{array}$ & 0.888 & & \\
\hline $\begin{array}{l}\text { I would invest more in digital } \\
\text { technologies if access to digital } \\
\text { consulting services was more } \\
\text { convenient (price and/or quality) }\end{array}$ & 0.775 & & \\
\hline $\begin{array}{l}\text { I would invest more in digital } \\
\text { technologies if support from the } \\
\text { government was higher (advisory } \\
\text { and consulting services) }\end{array}$ & 0.753 & & \\
\hline $\begin{array}{l}\text { If I had higher financial availability, I } \\
\text { would invest more in digital } \\
\text { technology for my farm }\end{array}$ & 0.701 & & \\
\hline $\begin{array}{l}\text { In the place where I live, investing in } \\
\text { new technological innovations is an } \\
\text { element of appreciation and respect }\end{array}$ & 0.616 & & \\
\hline $\begin{array}{l}\text { I know many competitors that are } \\
\text { investing in digital technology for } \\
\text { their farm }\end{array}$ & & & \\
\hline $\begin{array}{l}\text { I would invest more in digital } \\
\text { technology if connectivity was more } \\
\text { reliable }\end{array}$ & & 0.851 & \\
\hline $\begin{array}{l}\text { I would invest more in digital } \\
\text { technologies if the } \\
\text { quality/convenience of } \\
\text { communication services was higher }\end{array}$ & & 0.773 & \\
\hline $\begin{array}{l}\text { I don't have connectivity problems } \\
\text { in my farm (phone, Internet) }\end{array}$ & & & \\
\hline $\begin{array}{l}\text { I have employees dedicated to the } \\
\text { management and/or research of } \\
\text { new digital technology for my farm }\end{array}$ & & & \\
\hline $\begin{array}{l}\text { How often I look for information } \\
\text { about agricultural digital } \\
\text { technologies on Internet }\end{array}$ & & & 0.871 \\
\hline $\begin{array}{l}\text { How often I go to events on digital } \\
\text { technology for agriculture }\end{array}$ & & & 0.844 \\
\hline $\begin{array}{l}\text { How often I read articles about } \\
\text { digital technology for agriculture }\end{array}$ & & & 0.727 \\
\hline $\begin{array}{l}\text { How often I contact/meet digital } \\
\text { technology providers }\end{array}$ & & & \\
\hline
\end{tabular}




\begin{tabular}{|c|c|c|c|c|}
\hline & Component 4 & Component 5 & Component 6 & Component 7 \\
\hline & $\begin{array}{c}\text { Perception Tech } \\
\text { Usefulness }\end{array}$ & Business Services & $\begin{array}{c}\text { Economic Concern } \\
\text { Perception }\end{array}$ & Cost Benefit Belief \\
\hline & $\alpha=0.52$ & $\alpha=0.4$ & $\alpha=0.50$ & $\alpha=$ N.A. \\
\hline $\begin{array}{l}\text { Digital technology is very } \\
\text { useful to } \\
\text { agriculture/livestock }\end{array}$ & 0.847 & & & \\
\hline $\begin{array}{l}\text { I believe that digital } \\
\text { technology } 4.0 \\
\text { brings/would bring real } \\
\text { benefits to my farm (higher } \\
\text { revenues and/or lower } \\
\text { costs) }\end{array}$ & 0.752 & & & \\
\hline $\begin{array}{l}\text { I don't want digital } \\
\text { technology in my farm } \\
\text { because I believe } \\
\text { agriculture should be more } \\
\text { traditional and "natural" }\end{array}$ & & & & \\
\hline $\begin{array}{l}\text { In my country the } \\
\text { government provides } \\
\text { incentives for investments } \\
\text { in digital technology for } \\
\text { agriculture (subsides, } \\
\text { lower taxes, other services) }\end{array}$ & & & & \\
\hline $\begin{array}{l}\text { I believe that accessing } \\
\text { communication services } \\
\text { (phone, Internet) is easy } \\
\text { and cheap }\end{array}$ & & 0.812 & & \\
\hline $\begin{array}{l}\text { I am fully satisfied with the } \\
\text { consulting services (IT and } \\
\text { digital) available to my } \\
\text { enterprise }\end{array}$ & & 0.647 & & \\
\hline $\begin{array}{l}\text { I have difficulties in } \\
\text { accessing financing (from } \\
\text { banks or private investors) }\end{array}$ & & & 0.875 & \\
\hline $\begin{array}{l}\text { I believe that digital } \\
\text { technologies } 4.0 \text { are too } \\
\text { expensive }\end{array}$ & & & 0.6 & \\
\hline $\begin{array}{l}\text { I believe that the cost of } \\
\text { digital technologies does } \\
\text { not offset their benefits } \\
\text { (higher revenues and/or } \\
\text { lower costs) }\end{array}$ & & & & 0.852 \\
\hline
\end{tabular}

Extraction Method: Principal Component Analysis.

Rotation Method: Varimax with Kaiser Normalization.

a Rotation converged in 17 iterations. 
TABLE 3

Descriptive Statistics

\begin{tabular}{|c|c|c|c|c|}
\hline Variables & Mean & St.Dev & Min & Max \\
\hline Technology adoption & 1.01 & 1.62 & 0 & 7 \\
\hline \multicolumn{5}{|l|}{ Land size } \\
\hline from 2.1 to 5 hectares & 0.14 & 0.34 & 0 & 1 \\
\hline from 5.1 to 10 hectares & 0.21 & 0.41 & 0 & 1 \\
\hline from 10.1 to 50 hectares & 0.40 & 0.49 & 0 & 1 \\
\hline from 50.1 to 100 hectares & 0.05 & 0.22 & 0 & 1 \\
\hline up to 100 hectares & 0.14 & 0.34 & 0 & 1 \\
\hline \multicolumn{5}{|l|}{ CEO Level of education } \\
\hline High School & 0.42 & 0.50 & 0 & 1 \\
\hline Bachelor degree & 0.11 & 0.32 & 0 & 1 \\
\hline Master degree & 0.23 & 0.42 & 0 & 1 \\
\hline Phd/Post graduate degree & 0.09 & 0.29 & 0 & 1 \\
\hline \multicolumn{5}{|l|}{ CEO Experience } \\
\hline $2-5$ years & 0.19 & 0.39 & 0 & 1 \\
\hline $6-10$ years & 0.21 & 0.41 & 0 & 1 \\
\hline $11-20$ years & 0.29 & 0.46 & 0 & 1 \\
\hline $21-50$ years & 0.21 & 0.41 & 0 & 1 \\
\hline$>50$ & 0.02 & 0.14 & 0 & 1 \\
\hline \multicolumn{5}{|l|}{ Number of Employees } \\
\hline $10-50$ & 0.09 & 0.29 & 0 & 1 \\
\hline $51-250$ & 0.02 & 0.14 & 0 & 1 \\
\hline Evidence based knowledge & 2.64 & 1.00 & 1 & 5 \\
\hline Contextual Factors & 3.08 & 0.87 & 1 & 5 \\
\hline Infrastructure Availability & 2.82 & 1.21 & 1 & 5 \\
\hline Business Services & 3.14 & 1.02 & 1 & 5 \\
\hline $\begin{array}{l}\text { Perception of technological } \\
\text { usefulness }\end{array}$ & 2.71 & 1.06 & 1 & 5 \\
\hline Economic Concerns Belief & 3.34 & 1.06 & 1 & 5 \\
\hline Cost-benefits Belief & 2.96 & 1.10 & 1 & 5 \\
\hline
\end{tabular}


TABLE 4

\section{Inter-correlation Matrix}

\begin{tabular}{|c|c|c|c|c|c|c|c|c|c|c|c|c|c|c|}
\hline & & 1 & 2 & 3 & 4 & 5 & 6 & 7 & 8 & 9 & 10 & 11 & 12 & 13 \\
\hline 1 & Technology adoption & 1 & & & & & & & & & & & & \\
\hline 2 & Contextual Factors & 0.1354 & 1 & & & & & & & & & & & \\
\hline 3 & $\begin{array}{l}\text { Infrastructure } \\
\text { Availability }\end{array}$ & -0.0017 & $0.3833^{*}$ & 1 & & & & & & & & & & \\
\hline 4 & Evidence based knowledge & $0.4244 *$ & 0.1863 & 0.1623 & 1 & & & & & & & & & \\
\hline 5 & $\begin{array}{l}\text { Perception of technological } \\
\text { usefulness }\end{array}$ & 0.1615 & $0.4863^{*}$ & $0.2463 *$ & 0.1951 & 1 & & & & & & & & \\
\hline 6 & Business Services & $0.2371 *$ & $0.3784^{*}$ & $0.4554^{*}$ & $0.3030 *$ & $0.2109 *$ & 1 & & & & & & & \\
\hline 7 & Economic Concerns Belief & 0.1363 & $0.3134^{*}$ & 0.1592 & $0.2603 *$ & $0.2710 *$ & $0.3070 *$ & 1 & & & & & & \\
\hline 8 & Cost-benefits Belief & -0.0233 & 0.0962 & -0.0471 & 0.0324 & $0.2599 *$ & 0.0516 & 0.1114 & 1 & & & & & \\
\hline \multicolumn{15}{|c|}{ Land size } \\
\hline 9 & from 2.1 to 5 hectares & -0.1916 & 0.1244 & 0.1794 & 0.0811 & -0.0514 & 0.037 & 0.0318 & -0.0681 & 1 & & & & \\
\hline 10 & from 5.1 to 10 hectares & -0.0192 & 0.1202 & 0.066 & 0.0205 & 0.0665 & 0.0577 & 0.1275 & 0.0195 & $-0.2030^{*}$ & 1 & & & \\
\hline 11 & from 10.1 to 50 hectares & -0.111 & 0.0206 & -0.0783 & $-0.2431^{*}$ & -0.0428 & -0.118 & -0.0681 & 0.0695 & $-0.3203^{*}$ & $-0.4152 *$ & 1 & & \\
\hline 12 & from 50.1 to 100 hectares & 0.0567 & -0.1153 & -0.0819 & 0.0525 & -0.003 & -0.1231 & -0.1423 & 0.0089 & -0.0928 & -0.1202 & -0.1897 & 1 & \\
\hline 13 & over 100 hectares & $0.2810^{*}$ & -0.1303 & -0.0674 & $0.3262 *$ & 0.0499 & 0.1714 & -0.0695 & -0.0681 & -0.1566 & $-0.2030^{*}$ & $-0.3203^{*}$ & -0.0928 & 1 \\
\hline
\end{tabular}




\begin{tabular}{|c|c|c|c|c|c|c|c|c|c|c|c|c|c|c|}
\hline & & 1 & 2 & 3 & 4 & 5 & 6 & 7 & 8 & 9 & 10 & 11 & 12 & 13 \\
\hline \multicolumn{15}{|c|}{ CEO Level of education } \\
\hline 14 & High School & 0.1651 & -0.0646 & -0.0802 & 0.1472 & 0.0092 & 0.0121 & 0.1197 & 0.0321 & -0.0875 & -0.0694 & 0.0072 & -0.0079 & 0.036 \\
\hline 15 & Bachelor degree & 0.0586 & 0.14 & 0.0198 & -0.0305 & 0.0358 & 0.0645 & -0.038 & -0.1054 & -0.1424 & -0.104 & 0.1769 & 0.0629 & 0.0488 \\
\hline 16 & Master degree & -0.0651 & 0.0365 & 0.0093 & -0.0209 & -0.1459 & -0.1575 & -0.0812 & 0.0207 & $0.2188^{*}$ & 0.0254 & 0.0148 & -0.0163 & -0.1434 \\
\hline 17 & Phd/Post graduate degree & -0.0687 & -0.0727 & 0.0555 & -0.0648 & 0.0366 & 0.0975 & -0.1035 & -0.0529 & 0.0816 & 0.099 & -0.1873 & -0.0754 & 0.186 \\
\hline \multicolumn{15}{|c|}{ CEO experience } \\
\hline 18 & 2-5 years & -0.1357 & -0.0341 & $0.2049^{*}$ & -0.034 & 0.1307 & -0.1293 & -0.0277 & -0.0061 & 0.0439 & $0.2136^{*}$ & -0.116 & 0.0075 & -0.1121 \\
\hline 19 & 6-10 years & 0.0763 & 0.0099 & 0.066 & $0.2188^{*}$ & -0.0553 & 0.0577 & -0.0919 & 0.0428 & 0.0219 & 0.0526 & -0.0481 & -0.1202 & 0.0968 \\
\hline 20 & 11-20 years & 0.1524 & 0.1083 & -0.0661 & -0.0199 & -0.0213 & -0.0853 & 0.0113 & -0.0174 & 0.014 & -0.1035 & 0.1367 & 0.0559 & -0.12 \\
\hline 21 & 21-50 years & -0.0352 & -0.1033 & $-0.2113^{*}$ & -0.0401 & 0.0056 & 0.0325 & -0.0188 & 0.0195 & -0.1281 & -0.0105 & 0.1093 & -0.0048 & 0.0968 \\
\hline 22 & $>50$ & 0.0443 & -0.0141 & 0.0066 & 0.1503 & 0.0397 & 0.0522 & -0.0469 & -0.1273 & -0.0577 & -0.0748 & -0.1181 & -0.0342 & $0.3686^{*}$ \\
\hline \multicolumn{15}{|c|}{ Number of employees } \\
\hline 23 & $10-50$ & -0.0687 & 0.0353 & 0.0258 & 0.091 & 0.0875 & -0.0252 & -0.0695 & -0.1505 & -0.0228 & 0.011 & -0.0411 & 0.0854 & 0.0816 \\
\hline 24 & $51-250$ & 0.1802 & 0.113 & 0.0521 & 0.1871 & 0.0743 & 0.0879 & 0.161 & 0.0055 & -0.0577 & -0.0748 & 0.0311 & $0.2940^{*}$ & -0.0577 \\
\hline
\end{tabular}




\begin{tabular}{|c|c|c|c|c|c|c|c|c|c|c|c|c|}
\hline \multicolumn{13}{|c|}{ CEO Level of education } \\
\hline 14 & High School & 1 & & & & & & & & & & \\
\hline 15 & Bachelor degree & $-0.3040^{*}$ & 1 & & & & & & & & & \\
\hline 16 & Master degree & $-0.4608^{*}$ & -0.1961 & 1 & & & & & & & & \\
\hline 18 & 2-5 years & -0.0271 & -0.089 & $0.3096^{*}$ & -0.0629 & 1 & & & & & & \\
\hline 19 & 6-10 years & 0.0347 & 0.1376 & -0.1577 & 0.187 & $-0.2464 *$ & 1 & & & & & \\
\hline 20 & 11-20 years & 0.0155 & -0.0869 & 0.1954 & -0.1278 & $-0.3083^{*}$ & $-0.3292 *$ & 1 & & & & \\
\hline 21 & 21-50 years & 0.1387 & -0.104 & $-0.2797^{*}$ & -0.077 & $-0.2464 *$ & $-0.2632 *$ & $-0.3292 *$ & 1 & & & \\
\hline 24 & $51-250$ & 00247 & 0.1765 & -0.0795 & -0.0469 & -0.0701 & 0.1048 & 0.0669 & -0.0748 & -0.0213 & -0.0469 & 1 \\
\hline
\end{tabular}


TABLE 5

Negative Binomial Regression

\begin{tabular}{|c|c|c|c|c|c|c|c|c|c|c|}
\hline \multirow[t]{2}{*}{ Variables } & \multicolumn{2}{|l|}{ Model 1} & \multicolumn{2}{|c|}{ Model 2} & \multicolumn{2}{|c|}{ Model 3} & \multicolumn{2}{|c|}{ Model 4} & \multicolumn{2}{|l|}{ Model 5} \\
\hline & Coef & $\begin{array}{c}\text { St. } \\
\text { Error }\end{array}$ & Coef & St. Error & Coef & $\begin{array}{c}\text { St. } \\
\text { Error }\end{array}$ & Coef & $\begin{array}{c}\text { St. } \\
\text { Error }\end{array}$ & Coef & $\begin{array}{c}\text { St. } \\
\text { Error }\end{array}$ \\
\hline \multicolumn{11}{|l|}{ Land size } \\
\hline from 2.1 to 5 hectares & $-1.927^{*}$ & 0.87 & $-2.269 *$ & 0.96 & $-1.855 * *$ & 0.71 & $-2.697 * * *$ & 0.74 & $-2.627 * * *$ & 0.75 \\
\hline from 5.1 to 10 hectares & -0.365 & 0.64 & -0.458 & 0.50 & -0.262 & 0.50 & $-1.106+$ & 0.68 & $-0.869+$ & 0.53 \\
\hline from 10.1 to 50 hectares & -0.754 & 0.63 & $-0.715+$ & 0.41 & -0.499 & 0.52 & -1.183 & 0.65 & $-0.878 * *$ & 0.41 \\
\hline from 50.1 to 100 hectares & -0.449 & 0.74 & -0.717 & 0.71 & 0.005 & 0.58 & -0.287 & 0.63 & -0.54 & 0.58 \\
\hline over 100 hectares & 0.555 & 0.68 & -0.167 & 0.51 & 0.777 & 0.56 & -0.032 & 0.67 & -0.344 & 0.44 \\
\hline \multicolumn{11}{|l|}{ CEO Level of education } \\
\hline High School & $0.856+$ & 0.48 & $0.916^{*}$ & 0.45 & $1.100 *$ & 0.51 & 0.878 & 0.58 & $1.212^{*}$ & 0.63 \\
\hline Bachelor degree & 0.919 & 0.60 & $1.328 *$ & 0.69 & $1.155+$ & 0.61 & 0.671 & 0.71 & 1298 & 0.82 \\
\hline Master degree & 0.875 & 0.62 & $1.034+$ & 0.61 & $1.397 *$ & 0.65 & 1.047 & 0.69 & $1.528^{*}$ & 0.76 \\
\hline Phd/Post graduate degree & -0.176 & 0.72 & 0.484 & 0.70 & -0.306 & 0.67 & -0.063 & 0.85 & 0.331 & 0.89 \\
\hline \multicolumn{11}{|l|}{ CEO experience } \\
\hline 2-5 years & 0.605 & 0.76 & -0.049 & 0.82 & 0.347 & 0.84 & $1.380+$ & 0.83 & -0.142 & 0.94 \\
\hline $6-10$ years & $1.355^{*}$ & 0.67 & 0.271 & 0.73 & $1.310+$ & 0.77 & $1.915 * *$ & 0.68 & 0.172 & 0.93 \\
\hline $11-20$ years & $1.513 * *$ & 0.62 & 0.777 & 0.68 & $1.242+$ & 0.73 & $2.069 * *$ & 0.63 & 0.627 & 0.79 \\
\hline 21-50 years & 0.836 & 0.68 & 0.147 & 0.75 & 0.773 & 0.78 & $1.488 *$ & 0.73 & 0.149 & 0.86 \\
\hline$>50$ & 0.794 & 1.07 & -0.325 & 1.27 & 0.725 & 1.00 & 1.277 & 0.84 & -0.61 & 1.17 \\
\hline \multicolumn{11}{|l|}{ Number of employees } \\
\hline $10-50$ & -0.206 & 0.75 & -0.412 & 0.89 & -0.442 & 0.77 & -0.084 & 0.73 & -0.605 & 0.85 \\
\hline $51-250$ & 0.715 & 0.61 & -0.109 & 0.56 & 0.124 & 0.54 & 0.130 & 0.56 & -0.305 & 0.49 \\
\hline Evidence based knowledge (HI) & & & $0.721 * * *$ & 0.18 & & & & & $0.679 * *$ & 0.23 \\
\hline $\begin{array}{l}\text { Perception of technological } \\
\text { usefulness }(H 2)\end{array}$ & & & & & $0.309 *$ & 0.14 & & & $0.242+$ & 0.14 \\
\hline Economic concerns $(H 2)$ & & & & & 0.201 & 0.15 & & & -0.159 & 0.17 \\
\hline Trade off cost-benefits $(H 2)$ & & & & & -0.112 & 0.14 & & & -0.091 & 0.15 \\
\hline Business Services (H3) & & & & & & & $0.553 * *$ & 0.18 & $0.394 *$ & 0.19 \\
\hline Contextual Factors (H3) & & & & & & & $0.429 *$ & 0.19 & 0.261 & 0.21 \\
\hline Infrastructure Availability (H3) & & & & & & & -0.145 & 0.15 & -0.064 & 0.15 \\
\hline Constant & $-1.431 *$ & 0.60 & $-2.726 * * *$ & 0.78 & $-2.925 * *$ & 1.07 & $-4.366^{* * *}$ & 1.02 & $-4.406 * *$ & 1.31 \\
\hline lnalpha & 0.014 & 0.41 & -0.489 & 0.59 & -0.168 & 0.52 & -0.348 & 0.51 & -1.085 & 0.97 \\
\hline alpha & 1.014 & 0.41 & 0.613 & 0.36 & 0.845 & 0.44 & 0.706 & 0.36 & 0.337 & 0.33 \\
\hline Wal chi2(df) & $47.31(16)$ & & $71.26(17)$ & & $69.36(19)$ & & $93.76(19)$ & & 97.57 (23) & \\
\hline Prob $>$ chi2 & 0.0001 & & 0.0001 & & 0.0001 & & 0.0001 & & 0.0001 & \\
\hline$A I C(d f)$ & $274.341(18)$ & & $262.384(19)$ & & $274.536(21)$ & & $267.114(21)$ & & $263.040(25)$ & \\
\hline$B I C(d f)$ & $320.498(18)$ & & $311.107(19)$ & & $328.387(21)$ & & $320.966(21)$ & & $327.148(25)$ & \\
\hline$N$ & 96 & & 96 & & 96 & & 96 & & 96 & \\
\hline
\end{tabular}

$+\mathrm{p}<0.10, * \mathrm{p}<0.05, * * \mathrm{p}<0.01, * * * \mathrm{p}<0.001$ 